\title{
The liquid level measurement of ultra low temperature cylinder based on the relative capacity method
}

\author{
Li Dangjuan ${ }^{1, a}$, Liu Tang ${ }^{1, b}$, Wu Shenjiang ${ }^{1, c}$, Xu Huan ${ }^{1, d}$ and Wu Bin ${ }^{2, e}$ \\ ${ }^{1}$ School of Optoelectronics Engineering, Xi'an Technology University, Xi'an 710021 \\ ${ }^{2}$ Xi'an Gauss Laser Technology Limited Company, Xi'an 710032 \\ a email:xxatu@163.com, bemail:aata@foxmail.com, cemail:bxait@163.com, demail:xuexi2012@qq. \\ com, eemail:aguang1121.126@qq.com
}

Keywords: Liquid Nature Gas (LNG), capacitance signal, liquid level measurement, processing circuit .

\begin{abstract}
The probe and measurement circuit for the liquid level measurement of ultra low temperature cylinder was designed. Liquid Nature Gas( LNG) sensor is a coaxial capacitance sensor which was used with the material of 304 stainless steel. Teflon was used as an insulating material to isolate the stainless steel sleeve and to realize the coaxial positioning. The circuit was designed based on 7555 timer and STM32 chip, combining the embedded technology to convert the capacitance of the sensor to the pulse signal output. the height and fuel allowance were calculated based on relative capacity method. The experimental results shows that the measuring circuit can converted the capacitance signal of the sensor to pulse signals reliably and stably, the expected measurement accuracy is less than $0.6 \%$.
\end{abstract}

\section{Introduction}

Liquefied natural gas (LNG) is becoming one of the prominent clean energy sources with its abundance, high calorific value, and low emission and price ${ }^{[1-3]}$. The gas vehicles which used with LNG have been put into operation. LNG vehicle cylinders have been gradually used in vehicles, trains, ships and aircraft and other transportation vehicles. Nowadays the total liquefied natural gas (LNG) production capacity has reached $290 \mathrm{Mt} / \mathrm{year}^{[4-9]}$. LNG vehicles need to display the LNG fuel parameters on the instrument panel, this can help the driver to know the usage of LNG and the rest of the situation at any time to ensure reliable and safe driving ${ }^{[10-14]}$.

The traditional fuel sensor drives the electromagnet with the float, thus the dry reed switch on or off producing changing resistance value to measure the oil level, but this method is not suit to LNG measurements because the LNG storage temperature is below $-162^{\circ} \mathrm{C}$ and it is sealed storage. The general liquid level detecting device is difficult to resist the pressure caused by this kind of ultra low temperature environment, so it requires to research the sensor, transmitter and display device based on the characteristics of LNG gas cylinder ${ }^{[15-16]}$. In particular, the processing of capacitance signal will directly affect the measurement accuracy of liquid level under the ultra low temperature ${ }^{[17]}$.

\section{The measurement principle}

According to different materials, the structure of capacitive sensor and the measurement principle are different. The structures are divided into two types: parallel metal plate and coaxial cylindrical. Parallel plate capacitor is the most widely used and the most common, but the cylinder rod type is the best choice, good accuracy, good stability, good resolution in the liquid capacitance sensor. The liquid level measurement principle of the sealed storage in the ultra low temperature environment is shown in Fig.1. When the ultra low temperature liquid level changes, the dielectric constant of the low temperature liquid will be changed, so the capacitance value is changed, and then liquid level will be calculated by the measuring device according to the changing capacitance value. 


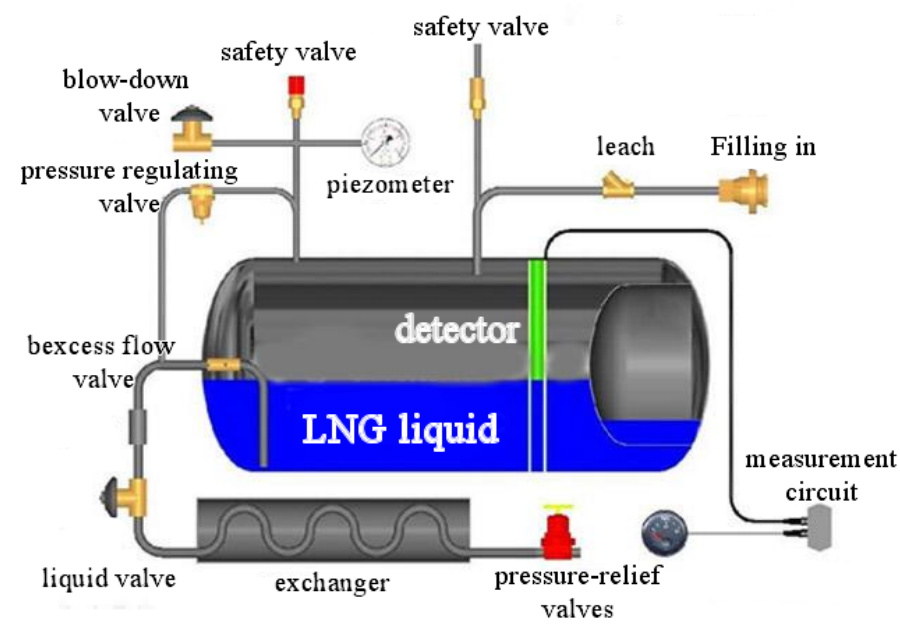

Fig.1 Vehicle LNG tank

The basic structure of the non-conducting liquid capacitance sensor is shown in Fig2. It is composed of two coaxial cylindrical stainless steel tube, the upper and lower ends of the two tubes are both fixed with the insulation materials to form coaxial structure. There is a mall hole in the bottom of the outer tube which can allow the liquid to flow freely. The liquid is insulated, PTFE insulation material isolate from the metal cylinder, there are many liquid holes distributed overall the cylinder which can keep the same level inside and outside. The inner metal tube and the coaxial sleeve form two electrodes, the capacitance is only related to the liquid level, and it has nothing to do with the physical structure of the storage tank. When the liquid flows, it changes the dielectric of the capacitor and the capacitance value of the capacitor will be changed. The liquid level can be measured according to this principle .

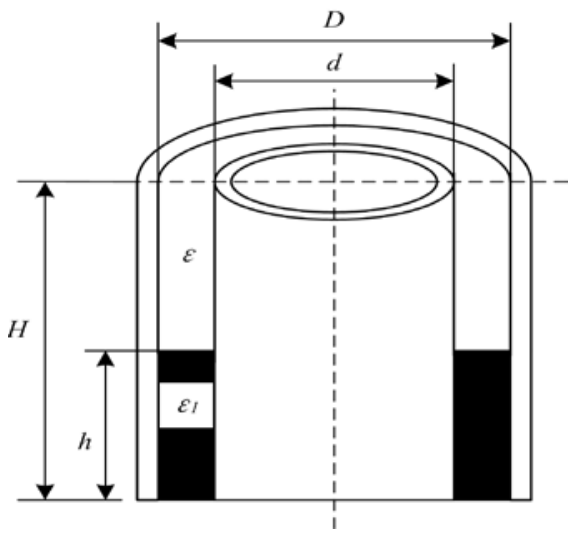

Fig.2 the structure of capacitive sensor

The liquid flows between the two tubes , the liquid level determines the change of capacitance and has nothing to do with the dielectric constant of the liquid. Therefore, the value of the liquid level can be calculated by calculating the value of the capacitor.

$$
C=C_{1}+C_{2}=\frac{2 \pi \varepsilon_{1} \varepsilon}{\ln (D / d)} h+\frac{2 \pi \varepsilon_{n}\left(\varepsilon_{1}-\varepsilon\right)}{\ln (D / d)} H
$$

Here $\varepsilon$ is the relative permittivity of the gas inside the tank, $\varepsilon_{1}$ is relative permittivity of the liquid fuels. It can be seen that the height of the liquid level is linear with the capacitance value.

The conversion relationship between capacitance of the coaxial capacitance sensor and liquid level is $C=\frac{2 \pi \varepsilon \varepsilon_{0}}{\ln (D / d)} h$, Here $\varepsilon_{0}$ is the permittivity vacuum dielectric constant, ${ }^{\varepsilon}$ relative permittivity of the insulating medium. $\mathrm{d}$ and $\mathrm{D}$ are respectively the inner diameter and outer diameter of the capacitance sensor, $\mathrm{h}$ is the height of liquid level. According to the formula, the total capacitance of the sensor can be obtained: 


$$
C=C_{1}+C_{2}=\frac{2 \pi \varepsilon \varepsilon_{0}}{\ln (D / d)}(L-H)+\frac{2 \pi \varepsilon_{1} \varepsilon_{0}}{\ln (D / d)} H
$$

Here $\varepsilon$ is the relative permittivity of the gas inside the bottle, $\varepsilon_{1}$ is relative permittivity of the liquid fuels. When the fuel height in the bottle is changed from zero to $\mathrm{H}$, the sensor capacitance value is :

$$
\sigma C=\frac{2 \pi \varepsilon_{0}\left(\varepsilon_{1}-\varepsilon\right)}{\ln (D / d)} H
$$

Table 1

\begin{tabular}{cccc}
\hline parameters & value & parameters & value \\
\hline outer cylinder diameter & $44.5 \mathrm{~mm}$ & thickness & $2.5 \mathrm{~mm}$ \\
iinner cylinder diameter & $22 \mathrm{~mm}$ & height & $591 \mathrm{~mm}$ \\
empty bottle capacitance value & $130 \mathrm{pf}$ & material & 304 stainless steel \\
Full bottle capacitance value & $215 \mathrm{pf}$ & weight & $1350 \mathrm{~g}$ \\
Signal wire diameter & $2.5 \mathrm{~mm}$ & Insulating layer & Teflon \\
\hline
\end{tabular}

PTFE is used for The communication cable and the insulation material. PTFE is a kind of synthetic polymer material, it is more commonly used in plastic materials and has good resistance to low temperature and mechanical properties. When the temperatures drop to $-196{ }^{\circ} \mathrm{C}$, it still has good elongation, which can work well in a wide range of temperature.

\section{Circuit design}

The structure of the ultra low temperature capacitive liquid level gauge measuring device includes three parts: the capacitance sensor, the transmitter circuit board and the man-machine interactive display module, the overall frame of the device is shown in Fig. 3.

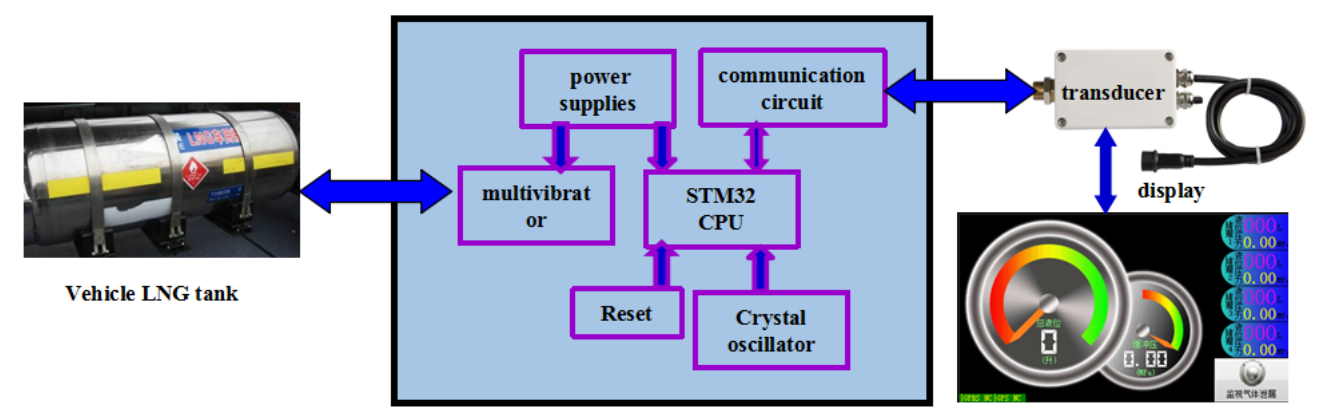

Fig.3 overall schematic diagram

Based on the multi-harmonic oscillator, the capacitance signal is converted into a pulse frequency signal by using a capacitor. the relationship between frequency and capacitance is shown as formula (4) and (5). The pulse width of the pulse signal is detected by testing the time of the pulse signal high level. The pulse width can be achieved by the use of micro controller internal timer. The tested pulse signals are output from the multi - harmonic oscillator to the microprocessor, these pulse signals are regarded as an external interrupt by the microprocessor. When the pulse signal rising edge is detected, it starts counting; when the pulse signal falling edge is detected, it stops counting; The measured value of the timer is multiplied by the machine cycle, then the pulse width is obtained. Oscillation period $\mathrm{T}$ is the sum of add $T_{1}$ and $T_{2} . T_{1}$ is the charging time for capacitor, $T_{2}$ is the discharge time.

the charging time:

the discharge time:

$$
T_{1}=\left(R_{1}+R_{2}\right) C \ln 2 \approx 0.7\left(R_{1}+R_{2}\right) C
$$




$$
T_{2}=R_{2} C \ln 2 \approx 0.7 R_{2} C
$$

oscillation period of rectangular wave:

$$
T=T_{1}+T_{2}=\ln 2\left(R_{1}+2 R_{2}\right) C \approx 0.7\left(R_{1}+2 R_{2}\right) C
$$

the period and frequency of the square wave output can be changed by changing the value of the $R_{1}, R_{2}$, and C. The value of capacitance is obtained which can calculate the height of the fuel level, and the function of the fuel volume and fuel level in bottle is fixed. Then, the purpose of calculating the residual fuel in the bottle by measuring the capacitance value is reached.

\section{Experiment and discussion}

Selecting $5 \%$ precision ceramic capacitor as the measured capacitance, Signal Vout is square wave signal. the waveform of the signal was recorded and the signal cycle was measured by signal generator .

\begin{tabular}{ccccc}
\multicolumn{5}{c}{ Table 2 capacitance measurement data table } \\
\hline $\begin{array}{c}\text { Nominal } \\
\text { capacitance } \\
(\mathrm{pF})\end{array}$ & $\begin{array}{c}\text { High level time } \\
(\mathrm{mS})\end{array}$ & $\begin{array}{c}\text { Capacitance } \\
\text { calculation } \\
(\mathrm{pF})\end{array}$ & $\begin{array}{c}\text { Relative range error } \\
(\%)\end{array}$ & $\begin{array}{c}\text { Relative } \\
\text { error } \\
(\%)\end{array}$ \\
\hline 0 & 0 & 0 & 0 & 0 \\
10 & 0.0016 & 11.42857 & 0.142857 & 14.28571 \\
140 & 0.02 & 142.8571 & 0.285714 & 2.040816 \\
330 & 0.044 & 314.2857 & -1.57143 & -4.7619 \\
610 & 0.08325 & 594.6429 & -1.53571 & -2.51756 \\
1080 & 0.1445 & 1032.143 & -4.78571 & -4.43122 \\
\hline
\end{tabular}

The error of the capacitance of the capacitor is $5 \%$, The deviation of the measurement results is also less than $5 \%$ when the capacitor capacity is up to $100 \mathrm{pF}$. The relative error is $14 \%$ when small capacitors is several tens of $\mathrm{PF}$, relative to other range, the measurement error is less than $1 \%$. the Subsequent calibration is needed for the existing measurement error still. Calibration method is:

(1) By linear fitting of the measured data , then the linear relationship between pulse width and capacitance can be obtained.

(2) the linear formula is written into the lower computer algorithm, then the output capacitance is the calibrated capacitance.

The fitted curve equation is as shown(7)

$$
y=7.431730 x-357.356393
$$

The corrected data are shown in Table 3. The maximum measurement error is $1.16 \mathrm{pf}$, the maximum error rate is $1.16 / 1000=0.16 \%$, the device is higher accuracy and smaller error for the overall measurement. The results of the calibration capacitor value and the liquid level value fitting are shown in Figure 3.

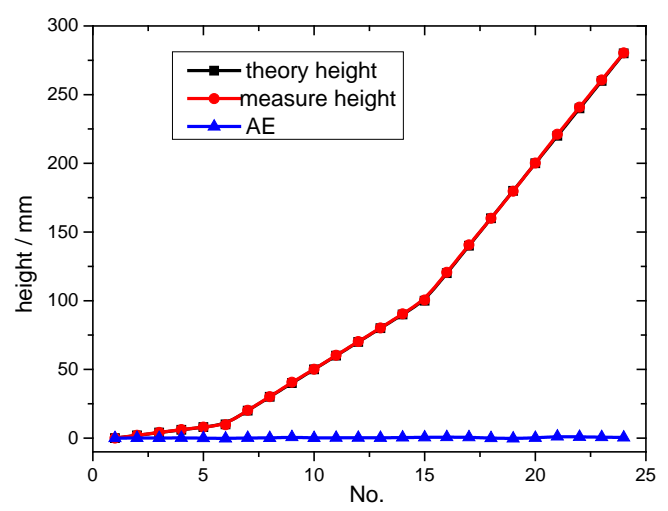

Fig. 3 the post calibration capacitor and its AE 
After calculation analysis, non conducting liquid level measurement in laboratory test , The average absolute error is about $0.713 \mathrm{~mm}$, the average error rate is $0.3 \%$, the maximum error is $1.2 \mathrm{~mm}$, the maximum error rate is only $0.6 \%$ compared with the whole range.

\section{Summary}

A LNG car bottle liquid level detection device was designed based on characteristics of LNG vehicle cylinder structure, LNG temperature and pressure, Error compensation and precise measurement were achieved for the cylindrical capacitor sensor capacitance signal based on relative capacitance method; the capacitance and pressure signal acquisition, filtering, amplification processing circuits were also designed, the multi harmonic oscillators carry out the information transmission which is composed of 7555 by digital quantity instead of analog quantity, and then the temperature drift, zero drift, and a variety of clutters would be eliminated. The standard 485/232 interface output is set up in the control system,. The test results show that the designed LNG in the liquid level monitoring system can meet the measurement accuracy requirements, it can improve the stability of the LNG vehicle to speed up the promotion of LNG vehicle in real life and ease the vehicle energy contradiction.

\section{Acknowledgments}

This research was supported by the college students innovation and entrepreneurship training program (Grant No. 201510702020 ) and the teaching reform project of Xi'an Technological University (Grant No. 15JGY03 ).

\section{References}

[1]. Kurle Y M, Wang S, Xu Q. Simulation study on boil-off gas minimization and recovery strategies at LNG exporting terminals[J]. Applied Energy, 2015, 156: 628-641.

[2]. Tomków Ł, Cholewiński M. Improvement of the LNG (liquid natural gas) regasification efficiency by utilizing the cold exergy with a coupled absorption-ORC (organic Rankine cycle)[J]. Energy, 2015, 87: 645-653.

[3]. He S, Chang H, Zhang X, et al. Working fluid selection for an Organic Rankine Cycle utilizing high and low temperature energy of an LNG engine[J]. Applied Thermal Engineering, 2015, 90: 579-589.

[4]. Cao W, Beggs C, Mujtaba I M. Theoretical approach of freeze seawater desalination on flake ice maker utilizing LNG cold energy[J]. Desalination, 2015, 355: 22-32.

[5]. Cheenkachorn K, Poompipatpong C, Ho C G. Performance and emissions of a heavy-duty diesel engine fuelled with diesel and LNG (liquid natural gas)[J]. Energy, 2013, 53: 52-57.

[6]. Reddick K, Belhateche N. The LNG (liquid natural gas) feed stream is split with at least one portion used as an external reflux, without prior treatment, to improve the separation and recovery of the natural gas liquids: U.S. Patent 6,941,771[P]. 2005-9-13.

[7]. Anay L H. Luketa-Hanlin, Anay. A review of large-scale LNG spills experiments and modeling[J]. Journal of Hazardous Materials, 2006,132(2):119-140.

[8]. Reddick K, Belhateche N. Liquid natural gas processing: U.S. Patent 6,604,380[P]. 2003-8-12.

[9]. Ronald P K, Donald L E. Lessons learned from LNG safety research[J]. Journal of Hazardous Materials, 2007,140(3):412-428.

[10]. Brighton P W, Byrne A J, Cleaver R P, et al. Comparison of heavy gas dispersion models for instantaneous releases[J]. J Hazardous Mat,1994, 36(3):193-208. 
[11]. Daish N C, Britter R E, Linden P F, et al. SMEDIS:Scientific model evaluation of dense gas dispersion models[J]. Int J Envir Pollution, 2000,14(1-6):39-51.

[12]. Phil C, Mike J, Ben H. A summary of some experimental data on LNG safety[J]. Journal of Hazardous Materials, 2007, 140(3): 429-438.

[13]. Hansen O R, Melheim J A, Storvik I E. CFD-Modeling of LNG Dispersion Experiments [C]// 2007 AIChE Spring National Meeting-Conference Proceedings. Houston, Texas: AIChE, 2007.

[14]. Gaveili F, Bullister E, Kytomaa H. Application of CFD (Fluent) to LNG spills into geometrically complex environments[J]. Journal of Hazardous Materials, 2008,159(1):158-168.

[15]. Hansen O R, Gavelli F, Iehard M, et al. Validation of FLACS against experimental data sets from the model evaluation database for LNG vapor dispersion[J].Journal of Loss Prevention in the Process Industries, 2010,23(6),857-877.

[16]. Yoshihide Tominaga, Akashi Mochida, Ryuichiro Yoshie, et al. All guidelines for practical applications of CFD to pedestrian wind environment around buildings[J]. Journal of Wind Engineering and Industrial Aerodynamics, 2008,96(10): 1749-1761.

[17]. Lotsberg I. Assessment of fatigue capacity in the new bulk carrierand tanker rules[J].Marine Structures, 2006,19(1):83-96. 